\title{
Can melatonin prevent or improve metabolic side effects during antipsychotic treatments?
}

\author{
This article was published in the following Dove Press journal: \\ Neuropsychiatric Disease and Treatment \\ 10 August 2017 \\ Number of times this article has been viewed
}

\author{
Maria-Cristina Porfirio' \\ Juliana Paula Gomes de \\ Almeida ${ }^{2}$ \\ Maddalena Stornelli' \\ Silvia Giovinazzo' \\ Diane Purper-Ouakil ${ }^{3}$ \\ Gabriele Masi ${ }^{4}$ \\ 'Unit of Child Neurology and \\ Psychiatry, "Tor Vergata" University of \\ Rome, Italy; ${ }^{2}$ Unit of Child Neurology, \\ Irmandade Santa Casa de Misericordia \\ Hospital São Paulo, Brazil; ${ }^{3}$ Unit of \\ Child and Adolescent Psychiatry, \\ Saint Eloi Hospital, Montpellier, \\ France; ${ }^{4}$ IRCCS Stella Maris, Scientific \\ Institute of Child Neurology and \\ Psychiatry, Calambrone, Pisa, Italy
}

Correspondence: Silvia Giovinazzo Unit of Child Neurology and Psychiatry, "Tor Vergata" University of Rome, Viale Oxford, 8I, 00133 Rome, Italy

Tel +390620900249

Email neuro.infantile@ptvonline.it

\begin{abstract}
In the last two decades, second-generation antipsychotics (SGAs) were more frequently used than typical antipsychotics for treating both psychotic and nonpsychotic psychiatric disorders in both children and adolescents, because of their lower risk of adverse neurological effects, that is, extrapyramidal symptoms. Recent studies have pointed out their effect on weight gain and increased visceral adiposity as they induce metabolic syndrome. Patients receiving SGAs often need to be treated with other substances to counteract metabolic side effects. In this paper, we point out the possible protective effect of add-on melatonin treatment in preventing, mitigating, or even reversing SGAs metabolic effects, improving quality of life and providing safer longterm treatments in pediatric patients. Melatonin is an endogenous indolamine secreted during darkness by the pineal gland; it plays a key role in regulating the circadian rhythm, generated by the suprachiasmatic nuclei $(\mathrm{SCN})$ of the hypothalamus, and has many other biological functions, including chronobiotic, antioxidant and neuroprotective properties, anti-inflammatory and free radical scavenging effects, and diminishing oxidative injury and fat distribution. It has been hypothesized that SGAs cause adverse metabolic effects that may be restored by nightly administration of melatonin because of its influence on autonomic and hormonal outputs. Interestingly, atypical anti-psychotics (AAPs) can cause several sleep disorders, and circadian misalignment can influence hormones involved in the metabolic regulation, such as insulin, leptin, and ghrelin; furthermore, a relationship between obesity and sleep curtailment has been demonstrated, as well as sleep deprivation in rats has been associated with hyperphagia. Metabolic effects of melatonin, both central and peripheral, direct and indirect, target most metabolic disorders reported during and after SGA treatment in children, adolescents, and adults. Further systematic studies on psychiatric patients are needed to explore the effect of add-on melatonin on metabolic side effects of SGAs, independent of energy intake, diet, and exercise.
\end{abstract}

Keywords: melatonin, metabolic syndrome, second-generation antipsychotics

\section{Introduction}

Antipsychotic drugs are frequently used for treating both psychotic and nonpsychotic psychiatric disorders, including schizophrenia, bipolar disorders, autism spectrum disorders, disruptive behavior disorders, and Tourette syndrome in children and adolescents, as well as in adults. ${ }^{1}$ In the last two decades, newer antipsychotics, usually named atypical antipsychotics (AAPs), or second-generation antipsychotics (SGAs), were thought to be safer than older, typical, first-generation antipsychotics (eg, haloperidol), mainly due to a lower risk because of neurological adverse reactions, namely, extrapyramidal symptoms (EPS). ${ }^{2,3}$ However, recent studies have raised significant concerns regarding their adverse effects related to the metabolic syndrome (MS) (weight gain/obesity, hypercholesterolemia, hypertriglyceridemia, hyperlipidemia, hyperglycemia/hyperinsulinism, and hypertension). ${ }^{4-6}$ Substantial weight gain and 
increased visceral adiposity have become a primary reason of concern. ${ }^{7}$ Furthermore, hyperglycemia/hyperinsulinism, hypercholesterolemia/hypertriglyceridemia, and hypertension are associated with a high risk for diabetes mellitus, cardiovascular diseases, and overall mortality. ${ }^{8-10}$

MS is defined by the presence of at least three of the following symptoms: waist circumference $>102 \mathrm{~cm}$ in males and $>88 \mathrm{~cm}$ in females, triglycerides $>150 \mathrm{mg} \mathrm{dL}^{-1}$, high density lipoprotein $<40 \mathrm{mg} \mathrm{dL}^{-1}$, blood pressure $(\mathrm{BP})>130$ $85 \mathrm{mmHg}$, and fasting glucose $>110 \mathrm{mg} \mathrm{dL}^{-1} \cdot{ }^{11,12}$ Pathways from antipsychotic drugs to metabolic effects may be increased appetite, decreased thermogenesis, interaction with several neurotransmitter receptors, modulation of neuropeptides, and alteration of circadian rhythm. ${ }^{13}$

Appetite stimulation is probably a key element of AAPinduced weight gain, and genetic polymorphisms strongly affect the bodyweight response. Nutritional advice, programmed physical activity, cognitive--behavioral training, and atypical antipsychotic switching are possible interventions to counteract excessive body weight gain. Furthermore, pharmacological adjunctive treatments have been assessed in some clinical trials, as shown in Table 1. Other molecules (agents, substances) are needed to effectively counteract metabolic side effect of AAPs.

Melatonin is an endogenously produced indolamine secreted by the pineal gland into the blood stream and cerebral fluid. It is also a natural component of some vegetables, cereals, and beverages, ${ }^{14}$ and can be taken as an exogenous supplement, chemically identical to its endogenous form. ${ }^{15}$
Endogenous melatonin is synthesized by pinealocytes from tryptophan via the serotonin pathway. ${ }^{16}$ The synthesis is enhanced by the binding of norepinephrine to adrenergic beta receptors usually during darkness, while its secretion is suppressed by light, ${ }^{17}$ namely, visible electromagnetic wavelengths in the range of $460-480 \mathrm{~nm} .{ }^{18}$ Its plasmatic level reaches maximal values in the middle of the night, and then progressively decreases to reach minimal values in the morning. Melatonin receptors MTNR1 and MTNR2 are mainly expressed in the hypothalamus, but also in other brain regions, ${ }^{12}$ and peripherically, in islets of Langerhans, where they are involved in regulating insulin secretion from $\beta$-cells and glucagon secretion from $\alpha$-cells. ${ }^{19}$

Circadian rhythm is generated by the suprachiasmatic nuclei ( $\mathrm{SCN}$ ) of the hypothalamus, which modulates in a circadian pattern the activity of noradrenergic neurons. Light perceived by the retina reaches the SCN through a nonvisual pathway, the retinohypothalamic tract, and suppresses melatonin secretion. ${ }^{16,17,20}$ Melatonin plays a key role in regulating the circadian rhythm ${ }^{21}$ and has many other biological functions, including chronobiotic, antioxidant and neuroprotective properties, and anti-inflammatory and free radical scavenging effects. Melatonin enhances the activity of antioxidant enzymes, diminishing oxidative injury and fat distribution..$^{22,23}$

\section{The hypothesis/theory}

A study showed that MT1 and vasopressin and/or vasoactive intestinal peptide positive cells were increased in the hypothalamic SCN and paraventricular nucleus (PVN) of

Table I Drugs to prevent or reverse atypical antipsychotic-induced bodyweight gain

\begin{tabular}{|c|c|c|}
\hline Drugs & Mechanism of action & Adverse effects \\
\hline Amantadine & $\begin{array}{l}\text { Stimulates dopamine effects and blocks } \\
\mathrm{N} \text {-methyl-D-aspartate receptor, } \\
\text { which decreases appetite }\end{array}$ & $\begin{array}{l}\text { Anxiety, insomnia, agitation, difficulty with concentration, exacerbation } \\
\text { of seizures, and psychiatric symptoms in patients with schizophrenia or } \\
\text { Parkinson's disease. Cases of suicidal ideation and livedo reticularis }\end{array}$ \\
\hline $\begin{array}{l}\text { Nizatidine, ranitidine, } \\
\text { famotidine }\end{array}$ & $\begin{array}{l}\mathrm{H} 2 \text { receptor antagonists, } \\
\text { which decrease appetite }\end{array}$ & $\begin{array}{l}\text { Constipation, diarrhea, headache, dizziness, dry mouth, rash, liver } \\
\text { toxicity, leukopenia, thrombocytopenia }\end{array}$ \\
\hline Topiramate & $\begin{array}{l}\text { Glutamatergic inhibition, which } \\
\text { decreases appetite }\end{array}$ & $\begin{array}{l}\text { Psychomotor slowing, sedation, somnolence, fatigue, memory problems, } \\
\text { dysphoria, acute myopia with secondary angle closure glaucoma, taste } \\
\text { perversion, metabolic acidosis, nephrolithiasis, and paresthesias }\end{array}$ \\
\hline Reboxetine & $\begin{array}{l}\text { Selective noradrenaline reuptake inhibitor } \\
\text { that promotes satiety }\end{array}$ & $\begin{array}{l}\text { Insomnia, dizziness, anxiety, agitation, dry mouth, constipation, urinary } \\
\text { hesitancy or retention, hypotension, and sexual dysfunction }\end{array}$ \\
\hline Sibutramine & $\begin{array}{l}\text { Blocks serotonin, noradrenaline, } \\
\text { and dopamine reuptake that } \\
\text { decreases appetite }\end{array}$ & $\begin{array}{l}\text { Dry mouth, nausea, abnormal taste, anorgasmia, delayed ejaculation, } \\
\text { gastric discomfort, constipation, sleep disturbances, dizziness, menstrual } \\
\text { pain, headache, flushing and joint/muscle pain, blood pressure and heart } \\
\text { rate elevation, cardiac arrhythmias, paraesthesia, sudden mood changes, } \\
\text { seizures, gastrointestinal/urinary pain or bleeding, jaundice, chest pain, } \\
\text { blurred vision, dyspnea, and edema }\end{array}$ \\
\hline Metformin & $\begin{array}{l}\text { Enhances insulin sensitivity that improves } \\
\text { carbohydrate and lipid metabolism }\end{array}$ & Gastrointestinal discomfort, loose stools \\
\hline
\end{tabular}

Note: Data from Baptista et al. ${ }^{81}$ 
patients with depressive disorders. ${ }^{24}$ Moreover, the number of MT1 cells, but not MT2, was positively correlated with disease duration, suggesting that it may increase during the course of the disease. These changes may contribute to the efficacy of MT1 agonists, as well as melatonin, to counteract metabolic vulnerability and may explain the baseline circadian disorders, which are both associated with depression; therefore, it could be considered as a model for other psychiatric diseases.

Newer antipsychotics have differential effects in hypothalamic structures. ${ }^{25}$ Romo-Nava et $\mathrm{al}^{26}$ hypothesized that SGAs may disturb a centrally mediated metabolic balance, causing adverse metabolic effects that may be restored by nightly administration of melatonin. The PVN is crucial for the regulation of metabolic functions, through hypothalamic signals conveyed to the body by hormones and the autonomic nervous system. ${ }^{27}$ These functions are strongly under the influence of the SCN, giving a circadian rhythm to autonomic and hormonal output. ${ }^{28}$

The SCN is one of the main targets of melatonin in the brain, as this hormone inhibits the neuronal firing of $\mathrm{SCN}$ neurons. ${ }^{19,29}$ Through the decreased activity of SCN neurons, those in the PVN are inhibited as well. A SCN-mediated mechanism could contribute to explain the SGA-induced adverse metabolic effects, and the positive action of melatonin in attenuating these effects. ${ }^{30}$

Recent studies on mammals demonstrated that melatonin supplementation can diminish the body weight of middleaged rats having melatonin deficiency, as well as in rats with diet-induced obesity. This weight loss is associated with a reduction in visceral obesity, hyperinsulinemia, and hyperleptinemia. ${ }^{31-33}$

Given these metabolic properties, and based on preliminary findings, ${ }^{9,21,26,34}$ we hypothesize that add-on melatonin may be a new possible approach in patients receiving antipsychotic drugs to prevent and/or reduce the risk of weight gain and other metabolic side effects. Moreover, given the high tolerability and low rate of side effects of exogenous melatonin, it may be also safely used in pediatric patients. The aim of this paper was to critically review empirical evidence and possible mechanisms supporting this strategy.

\section{Evaluation of the hypothesis}

There are just few studies, as we show in Table 2, suggesting that melatonin may reduce the metabolic side effects of antipsychotic drugs, independent of energy intake, diet, and exercise. ${ }^{18,34}$ First evidence was derived from experimental animal models. Raskind et $\mathrm{al}^{9}$ divided a sample of 44 female rats into four groups ( $\mathrm{n}=11$ group) and treated each group for 8 weeks with olanzapine, melatonin, olanzapine + melatonin, or placebo in drinking water, respectively. At 8 weeks, body weight and total visceral fat pad weight increased in rats treated with olanzapine alone more than the other three groups (all $P<0.01$ ), while the other three groups did not differ significantly. Furthermore, nocturnal plasma melatonin level was 55\% lower in olanzapine-treated rats compared with controls, and this level was restored to normal by melatonin replacement. Nocturnal locomotor activity decreased by $32 \%$ with olanzapine and was not restored by melatonin supply. Therefore, the authors suggest that olanzapine-metabolic effects may be, at least in part, due to olanzapine-induced changes in melatonin secretion and not only due to reduced locomotor activity.

Few studies have explored the effect of add-on melatonin on metabolic side effects of antipsychotic drugs based on data from clinical trials on psychiatric patients. In an 8-week, double-blind, randomized, placebo-controlled, parallel-group clinical trial, Romo-Nava et $\mathrm{al}^{26}$ evaluated the metabolic effect of melatonin in 44 SGA-treated patients (20 with bipolar disorder and 24 with schizophrenia), in terms of weight, BP, lipid, glucose, body composition, and anthropometric measures. Patients randomly received placebo $(n=24)$ or melatonin $5 \mathrm{mg}(\mathrm{n}=20)$. The melatonin group showed a decrease in diastolic BP (5.1 vs $1.1 \mathrm{mmHg}$ for placebo, $P=0.003)$ and attenuated weight gain (1.5 vs $2.2 \mathrm{~kg}$ for placebo, $\mathrm{F}=4.512, P=0.040$ ), compared with the placebo group. Of note, the significant beneficial effects of melatonin on fat mass ( $0.2 \mathrm{vs} 2.7 \mathrm{~kg}$, respectively, $P=0.032)$ and diastolic BP (5.7 vs $5.5 \mathrm{mmHg}$, respectively, $P=0.001$ ) were observed in the bipolar patients, but not in the schizophrenic group.

Furthermore, Romo-Nava et a ${ }^{26}$ found a different effect of melatonin in patients receiving antipsychotics with a medium risk of weight gain (quetiapine and risperidone), compared with the high-risk antipsychotics (clozapine and olanzapine). Melatonin effectively reduced weight gain in patients receiving medium-risk antipsychotics, while a greater weight gain was found with high-risk antipsychotics (effect sizes for medium-risk SGAs: placebo group vs melatonin group: 0.271; and for high-risk SGAs: placebo group vs melatonin group: -0.281 ). These patients showed a significantly greater increase in total body water compared with the placebo group, an effect that could account for the apparent weight and waist size increases caused by antipsychotics (effect sizes for medium-risk SGAs: placebo group vs melatonin group: 0.14; and for high-risk SGAs: placebo group vs melatonin group: -0.461 ). 
Table 2 Pharmacological studies comparing melatonin versus placebo to prevent/reverse atypical antipsychotic-induced metabolic syndrome

\begin{tabular}{|c|c|c|c|c|}
\hline Studies & Sample & Treatment (dosage) & $\begin{array}{l}\text { Trial duration } \\
\text { (weeks) }\end{array}$ & Results \\
\hline \multirow[t]{4}{*}{$\begin{array}{l}\text { Raskind } \\
\text { et } \text { al }^{9}\end{array}$} & 44 rats & $\begin{array}{l}\text { I I patients, olanzapine } \\
(2 \mathrm{mg} / \mathrm{kg} / \text { day })\end{array}$ & 8 & $\begin{array}{l}\text { Higher weight in the olanzapine group than in each of the } \\
\text { other groups (all } P<0.00 \text { I) }\end{array}$ \\
\hline & & II patients, melatonin & & $\begin{array}{l}\text { Total visceral fat pad weight was increased } \sim 37 \%(P<0.00 \text { I }) \\
\text { by olanzapine and restored to control levels by olanzapine }+ \\
\text { melatonin }\end{array}$ \\
\hline & & $\begin{array}{l}\text { II patients, olanzapine }+ \\
\text { melatonin }\end{array}$ & & $\begin{array}{l}\text { Nocturnal plasma melatonin concentrations in week } 7 \text { of } \\
\text { treatment were suppressed } 55 \%(P<0.00 \mathrm{I}) \text { in the olanzapine- } \\
\text { treated rats, relative to control treatment, and were restored } \\
\text { to normal by olanzapine + melatonin treatment }\end{array}$ \\
\hline & & II patients, placebo & & $\begin{array}{l}\text { Nocturnal locomotor activity was decreased } 32 \%(P<0.00 \mathrm{I}) \\
\text { by olanzapine and addition of melatonin treatment did not } \\
\text { alter this decrease }\end{array}$ \\
\hline \multirow[t]{4}{*}{$\begin{array}{l}\text { Romo-Nava } \\
\text { et } \mathrm{al}^{26}\end{array}$} & $\begin{array}{l}44 \text { patients ( } 20 \text { with } \\
\text { bipolar disorder and } \\
24 \text { with schizophrenia) }\end{array}$ & $\begin{array}{l}20 \text { patients, slow-release } \\
\text { melatonin }(5 \mathrm{mg})\end{array}$ & 8 & $\begin{array}{l}\text { Decrease in diastolic } B P(5 . I \text { vs } I . I \mathrm{mmHg} \text { for placebo, } \\
P=0.003) \text { and attenuated weight gain (I.5 vs } 2.2 \mathrm{~kg} \text { for placebo, } \\
P=0.04) \text { in melatonin group }\end{array}$ \\
\hline & & 24 patients, placebo & & $\begin{array}{l}\text { Waist circumference changes between the placebo and } \\
\text { melatonin groups ( } 1.9 \text { vs } 2.2 \text {, respectively, } P=0.05)\end{array}$ \\
\hline & & $\begin{array}{l}\text { Antipsychotics } \\
\text { (clozapine, olanzapine, } \\
\text { quetiapine, risperidone) }\end{array}$ & & $\begin{array}{l}\text { In the bipolar disorder, but not in the schizophrenia group, } \\
\text { strong beneficial metabolic effects of melatonin in comparison } \\
\text { to placebo on fat mass ( } 0.2 \mathrm{vs} 2.7 \mathrm{~kg} \text {, respectively, } P=0.032) \\
\text { and diastolic BP ( } 5.7 \text { vs } 5.5 \mathrm{mmHg} \text {, respectively, } P=0.00 \mathrm{I}) \\
\text { were observed }\end{array}$ \\
\hline & & $\begin{array}{l}\text { Concomitant medications } \\
\text { (lithium, valproate, SSRI, } \\
\text { benzodiazepines) }\end{array}$ & & \\
\hline \multirow[t]{3}{*}{$\begin{array}{l}\text { Modabbernia } \\
\text { et } \mathrm{al}^{34}\end{array}$} & $\begin{array}{l}48 \text { patients } \\
\text { (first-episode } \\
\text { schizophrenia) }\end{array}$ & $\begin{array}{l}24 \text { patients, melatonin } \\
(3 \mathrm{mg})\end{array}$ & 8 & $\begin{array}{l}\text { Melatonin was associated with significantly less weight gain } \\
(M D=3.2 \mathrm{~kg}, P=0.023) \text {, increase in waist circumference } \\
(M D=2.83 \mathrm{~cm}, P=0.04 \mathrm{I}) \text {, in body mass index }(\mathrm{MD}=\mathrm{I} .07 \mathrm{~kg} / \\
\left.\mathrm{m}^{2}, P=0.024\right) \text {, and triglyceride concentration }(\mathrm{MD}=62 \mathrm{mg} \mathrm{dL}-1 \\
P=0.09) \text { than the placebo }\end{array}$ \\
\hline & & $\begin{array}{l}48 \text { patients, olanzapine } \\
(5-25 \mathrm{mg})\end{array}$ & & $\begin{array}{l}\text { Changes in cholesterol, insulin, and blood sugar } \\
\text { concentrations did not differ significantly between the two } \\
\text { groups }\end{array}$ \\
\hline & & & & \\
\hline
\end{tabular}

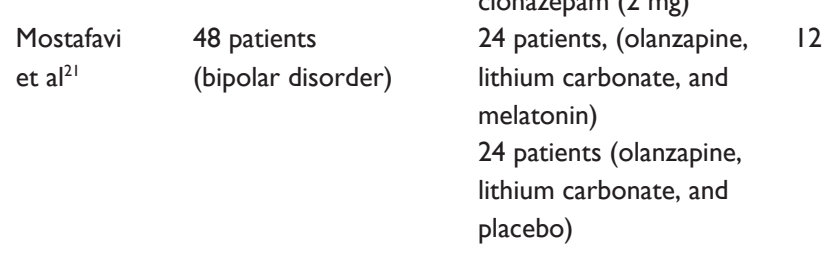

24 patients, placebo $(24)$

48 patients,

clonazepam (2 mg)

24 patients, (olanzapine, $\quad 12 \quad$ Fasting blood sugar and triglyceride demonstrated greater increase in the placebo group compared with the melatonin group, but the differences were not statistically significant Melatonin significantly inhibited the rise in total cholesterol levels compared with placebo $(P=0.032)$

Mean systolic BP rose more slowly in the melatonin group ( $1.05 \mathrm{mmHg})$ compared with placebo $(6.36 \mathrm{mmHg})(P=0.023)$ The trends in diastolic BP did not show any significant pattern

Abbreviations: BP, blood pressure; MD, mean difference; SSRI, selective serotonin reuptake inhibitors.

Modabbernia et $\mathrm{l}^{34}$ explored efficacy of melatonin $3 \mathrm{mg} /$ day in prevention of olanzapine-induced metabolic side effects in 48 patients with first-episode schizophrenia, randomly assigned to olanzapine plus either melatonin or placebo for 8 weeks. At the endpoint, melatonin was associated with significantly less weight gain (mean difference $[\mathrm{MD}]=3.2 \mathrm{~kg}, P=0.023$ ) and less increase in waist circumference ( $\mathrm{MD}=2.83 \mathrm{~cm}, P=0.041)$ than the placebo, while cholesterol, insulin, and blood sugar concentrations did not differ significantly between the groups.

Mostafavi et a ${ }^{21}$ studied effects of melatonin in reducing metabolic side effects of olanzapine in 48 adolescents (age range 11-17 years) with bipolar disorder, 24 patients allocated to olanzapine, lithium carbonate, and melatonin; and 
24 patients allocated to olanzapine, lithium carbonate, and placebo. Melatonin significantly inhibited the rise in total cholesterol levels compared with placebo $(P=0.032)$, while fasting blood sugar and triglycerides showed greater increase in the placebo group compared with the melatonin group but the differences were not statistically significant. Mean systolic BP rose more slowly in the melatonin group $(1.05 \mathrm{mmHg}) \mathrm{com}$ pared with placebo $(6.36 \mathrm{mmHg})(P=0.023)$, while the trends in diastolic blood pressure did not show any significance.

\section{Consequences of the hypothesis and discussion}

All melatonin functions, including regulation of the circadian rhythm, antioxidant, and anti-inflammatory properties, could represent possible mechanisms of body weight reduction. Adipose tissue is considered an endocrine organ, as adipocytes synthesize adipocytochines, including leptin and adiponectin, ${ }^{35}$ hemodynamic vascular factors, and chemokines. ${ }^{36,37}$ Obesity is characterized by low-grade inflammation generated by the activity of adipocytes and other cells ${ }^{38,39}$ and is associated with insulin resistance, given the increased concentration of free fatty acids (FFAs) in the blood stream and the antagonism of insulin action by adipocytokines. ${ }^{14}$ Furthermore, obesity and MS are associated with a chronic oxidative stress state and with activation of proinflammatory cytokines and prothrombotic mediators. ${ }^{31,40,41}$ These compounds reduce the activity of antioxidant enzymes, causing lipid peroxidation. Melatonin can enhance FFAs oxidation in the muscles, and thus increase insulin sensitivity and glucose tolerance, reduce the hepatic glucose production and eventually promote weight loss, ${ }^{35}$ and reduce plasma leptin levels and abdominal fat. ${ }^{32,35}$ Furthermore, melatonin reduces oxidative stress by several mechanisms, such as free radical scavenging and stimulation of antioxidant enzymes. ${ }^{42}$

Additionally, melatonin can counteract some metabolic disturbances through regulation of circadian rhythms. ${ }^{9}$ At least $10 \%$ of cellular transcription changes have a circadian cycle. Molecular studies have demonstrated a correlation between clock genes and metabolism regulation, including the control of glucose homeostasis, ${ }^{43}$ lipid synthesis, ${ }^{44}$ and adipogenesis. ${ }^{45}$ It has been reported that pinealectomy produces glucose intolerance and reduced insulin secretion by isolated pancreatic islets. ${ }^{46}$ Therefore, circadian misalignment can influence hormones involved in metabolic regulation, such as insulin, leptin, and ghrelin. ${ }^{47}$ Sleep deprivation in rats has been associated with hyperphagia ${ }^{48}$ and a relationship between obesity and sleep curtailment has been demonstrated. ${ }^{49}$ Interestingly, AAPs can cause several sleep disorders such as rhythm disturbances, restless leg syndrome, and night eating syndromes. ${ }^{50}$
Furthermore, it has been hypothesized that melatonin may be effective in the prevention of obesity by activation of brown adipose tissue (BAT). More specifically, melatonin can increase the capacity of nonshivering thermogenesis of BAT in small mammals. ${ }^{51}$ BAT is a highly active metabolic tissue, which can transform extra energy into heat through uncoupling oxidative phosphorylation in mitochondria. Melatonin can increase BAT activity and mass by different mechanisms, both central and peripheral. ${ }^{18}$ Indeed, BAT is regulated by hypothalamic neurons, especially the $\mathrm{SCN},{ }^{52-54}$ with its melatonin receptors. ${ }^{55-58}$ Furthermore, melatonin may act directly on BAT, as membrane melatonin receptors are located on brown adipocytes. Finally, another possible site of the action of melatonin in BAT is the mitochondria, where changes induced by melatonin cause an increase in brown fat cells proliferation, as well as an increase in their thermogenic capacity.

Melatonin has been associated with type 2 diabetes mellitus (T2DM), and it has been proposed that pancreatic receptors of $\beta$-cells for melatonin are coupled to three parallel signaling pathways, with three different influences on insulin secretion: 1) the cyclic adenosine monophosphate pathway, leading to the inhibition of insulin secretion; 2) the melatonin receptor 2 (MTNR2) pathway, inhibiting the guanylate cyclase/cyclic guanosine monophosphate pathway and therefore insulin secretion; and 3) the inositol triphosphate (IP3) pathway, which augments insulin by mobilizing calcium. ${ }^{59}$

A study in the Chinese population showed the impact of single-nucleotide polymorphisms on glucose metabolism and insulin secretion. ${ }^{60}$ The authors found that genotypes of the 2-catalytic subunit of glucose-6-phosphatase (G6PC2) and of melatonin receptor $1 \mathrm{~B}$ (MTNR1B) modulated fasting glucose levels in normoglycemic individuals, while variants of G6PC2 and glucokinase regulatory protein were associated with T2DM. Similarly, another study associated common variants of MTNR1B, G6PC2, and GCKP genotypes with elevated fasting glucose plasma levels and reduced insulin secretion. ${ }^{61}$ To conclude, these alleles can be responsible or perpetuate hyperglycemia in predisposed individuals.

Peripheral melatonin receptors MTNR1 and MTNR2 are expressed in islets of Langerhans and are involved in regulating insulin secretion from $\beta$-cells and glucagon secretion from $\alpha$-cells. A dyssynchrony of receptor signaling may induce the development of T2DM. A study on diabetic rat models showed that melatonin has also a diurnal impact on the blood glucose-regulating function of the islets, and an inverse relationship between melatonin and insulin has been found, with an increase in melatonin leading to a downregulation of insulin secretion and vice versa. ${ }^{62}$ 
However, despite the close relationship between insulin and melatonin, due to the effect of melatonin on the insulin secretion capacity of pancreatic islets, ${ }^{35,59}$ the relationship between melatonin and glucose metabolism is far from clear. Several studies have found that melatonin decreases glucose-induced insulin release in mice and rats. ${ }^{63}$ In this context, studies on rats found that the age-related decreased pineal secretion of melatonin was associated with intra-abdominal adiposity, as well as with elevated insulin and leptin levels, and that melatonin can prevent the aging-related increase in insulin resistance. ${ }^{64}$

One of the characteristic features of T2DM is the association between hyperglycemia and dyslipidemia, a well-known risk factor for endothelial cellular $\beta$-cell dysfunction. ${ }^{14}$ It has been suggested that postprandial hyperglycemia with high triglyceride levels, chylomicron remnants, and FFAs is implicated in the development of inflammation, and especially oxidative stress, which can, in turn, exacerbate the adverse effects of postprandial hyperglycemia. ${ }^{65}$ The elevation of blood FFA levels can be mitigated with melatonin supplementation, due to the stimulation of non-shivering thermogenesis in the BAT. Studies suggest that melatonin enhances the entry of FFAs into the mitochondria, significantly reducing their plasma levels. ${ }^{31,66}$ A positive effect of melatonin on blood levels of low-density lipoprotein (LDL) cholesterol, associated with protection from oxidation, ${ }^{67-70}$ may be mediated by inhibition of cholesterol absorption, ${ }^{71}$ enhancement of LDL-c receptor activity, inhibition of cholesterol synthesis, and increase of cholesterol catabolism into bile acids. ${ }^{72-74}$

Melatonin may contribute to lower BP, possibly through improved functioning of the biological clock. ${ }^{75}$ It has long been known that the systemic BP is variable and reduced (by $10 \%-20 \%$ ) during sleep in humans. ${ }^{15}$ However, the nocturnal fall in BP does not take place in $30 \%-35 \%$ of hypertensive patients, and it has been hypothesized that melatonin may be particularly relevant in these patients. ${ }^{46}$ This issue is important, as patients whose BP is not reduced at night may be at risk for insulin resistance, obesity, and coronary heart disease, ${ }^{76}$ and increased cardiovascular morbidity and mortality. ${ }^{77}$ This risk may be further enhanced during SGA treatment. Studies showed that melatonin administration ( $2.5 \mathrm{mg} /$ day) decreased nocturnal systolic BP and diastolic $\mathrm{BP}$ in hypertensive humans. ${ }^{75}$ Reduced inflammation of the interstitial kidney tissue and oxidative stress in spontaneous hypertensive rats may be implicated in this protective effect. ${ }^{78}$ The antioxidant effects may be the most important and influence BP via the specific pathways of receptors in peripheral vessels or in parts of the central nervous system.
Furthermore, several animal studies showed that melatonin had a hypotensive action by restoring norepinephrine concentration, the proportion of heart $\beta 1 / \beta 2$ receptors, ${ }^{79}$ and improving the maximum relaxation of mesenteric arteries. ${ }^{14}$ Another hypotensive mechanism may be through melatonin receptors in the hypothalamus, influencing the release of catecholamines, modulating the response of beta receptors, and enhancing endothelial nitric oxide synthase enzyme activation and nitric oxide synthesis. ${ }^{80}$

In conclusion, metabolic effects of melatonin, both central and peripheral, direct and indirect, target most of the disorders reported during and after SGA treatment in children, adolescents, and adults. ${ }^{4}$ These findings offer room for systematic studies addressing the crucial topic of the possible protective effect of add-on melatonin treatment in preventing, mitigating, or even reversing SGAs metabolic effects in order to improve quality of life of patients and provide safer longterm treatments, when these are absolutely needed.

\section{Acknowledgment}

This study was in part funded by the Italian Ministry of Health.

\section{Disclosure}

Dr Masi was in the advisory boards for Eli Lilly, Shire and Angelini, has received research grants from Eli Lilly, Shire, and Lundbeck, and has been a speaker for Eli Lilly, Shire, Lundbeck, and Otsuka. The other authors report no conflicts of interest in this work.

\section{References}

1. Olfson M, King M, Schoenbaum M. Treatment of young people with antipsychotic medications in the United States. JAMA Psychiatry. 2015; 72(9):867-874.

2. Leucht S, Pitschel-Walz G, Abraham D, Kissling W. Efficacy and extrapyramidal side-effects of the new antipsychotics olanzapine, quetiapine, risperidone and sertindole compared to conventional antipsychotics and placebo: a metaanalysis of randomized controlled trials. Schizophr Res. 1999;35(1):51-68.

3. Carton L, Cottencin O, Lapeyre-Mestre M, et al. Off-label prescribing of antipsychotics in adults, children and elderly individuals: a systematic review of recent prescription trends. Curr Pharm Des. 2015; 21(23):3280-3297.

4. Correll CU, Manu P, Olshanskiy V, Napolitano B, Kane JM, Malhotra AK. Cardiometabolic risk of second-generation antipsychotic medications during first-time use in children and adolescents. JAMA. 2009; 302(16): 1765-1773.

5. Maayan L, Correll CU. Weight gain and metabolic risks associated with antipsychotic medications in children and adolescents. J Child Adolesc Psychopharmacol. 2011;21(6):517-535.

6. De Hert M, Dobbelaere M, Sheridan EM, Cohen D, Correll CU. Metabolic and endocrine adverse effects of second-generation antipsychotics in children and adolescents: a systematic review of randomized, placebo controlled trials and guidelines for clinical practice. Eur Psychiatry. 2011;26(3):144-158. 
7. Wirshing DA, Wirshing WC, Kysar L, et al. Novel antipsychotics: comparison of weight gain liabilities. J Clin Psychiatry. 1999;60(6): 358-363.

8. Fontaine KR, Heo M, Harrigan EP, et al. Estimating the consequences of antipsychotic induced weight gain on health and mortality rate. Psychiatry Res. 2001;101:277-288.

9. Raskind MA, Burke BL, Crites NJ, Tapp AM, Rasmussen DD Olanzapine-induced weight gain and increased visceral adiposity is blocked by melatonin replacement therapy in rats. Neuropsychopharmacology. 2007;32(2):284-288.

10. Miron IC, Baroană VC, Popescu F, Ionică F. Pharmacological mechanisms underlying the association of antipsychotics with metabolic disorders. Curr Health Sci J. 2014;40(1):12-17.

11. Expert Panel on Detection, Evaluation, and Treatment of High Blood Cholesterol in Adults. Executive Summary of The Third Report of The National Cholesterol Education Program (NCEP) Expert Panel on Detection, Evaluation, and Treatment of High Blood Cholesterol in Adults. Adult Treatment Panel III. JAMA. 2001;285(19):2486-2497.

12. Cardinali DP, Cano P, Jiménez-Ortega V, Esquifino AI. Melatonin and the metabolic syndrome: physiopathologic and therapeutical implications. Neuroendocrinology. 2011;93(3):133-142.

13. Coccurello R, Moles A. Potential mechanisms of atypical antipsychoticinduced metabolic derangement: clues for understanding obesity and novel drug design. Pharmacol Ther. 2010;127:210e51.

14. Navarro-Alarcón M, Ruiz-Ojeda FJ, Blanca-Herrera RM, et al. Melatonin and metabolic regulation: a review. Food Funct. 2014;5(11): 2806-2832.

15. Mohammadi MR, Mostafavi SA, Keshavarz SA, et al. Melatonin effects in methylphenidate treated children with attention deficit hyperactivity disorder: a randomized double blind clinical trial. Iran J Psychiatry. 2012;7(2):87-92.

16. Wurtman RJ, Larin F, Axelrod J, Shein HM, Rosasco K. Formation of melatonin and 5-hydroxyindole acetic acid from 14C-tryptophan by rat pineal glands in organ culture. Nature. 1968;217(5132):953-954.

17. Cagnacci A. Melatonin in relation to physiology in adult humans. J Pineal Res. 1996;21(4):200-213.

18. Tan DX, Manchester LC, Fuentes-Broto L, Paredes SD, Reiter RJ. Significance and application of melatonin in the regulation of brown adipose tissue metabolism: relation to human obesity. Obes Rev. 2011; 12(3):167-188.

19. Reppert SM, Weaver DR, Ebisawa T. Cloning and characterization of a mammalian melatonin receptor that mediates reproductive and circadian responses. Neuron. 1994;13(5):1177-1185.

20. Sielaff T, Demisch L, Gebhart P, Blumhofer A, Khazai A, Lemmer B. Chronobiological effects of L-tryptophan in humans: influence on melatonin secretion. Adv Exp Med Biol. 1991;294:489-491.

21. Mostafavi A, Solhi M, Mohammadi MR, Hamedi M, Keshavarzi M, Akhondzadeh S. Melatonin decreases olanzapine induced metabolic side-effects in adolescents with bipolar disorder: a randomized double-blind placebo-controlled trial. Acta Med Iran. 2014;52(10): 734-739.

22. Rodriguez C, Mayo JC, Saint RM, et al. Regulation of antioxidant enzymes: a significant role for melatonin. J Pineal Res. 2004; 36(1):1-9.

23. De Filippis D, Iuvone T, Esposito G, et al. Melatonin reverses lipopolysaccharide-induced gastro-intestinal motility disturbances through the inhibition of oxidative stress. J Pineal Res. 2008;44(1):45-51.

24. $\mathrm{Wu} \mathrm{YH,} \mathrm{Ursinus} \mathrm{J,} \mathrm{Zhou} \mathrm{JN,} \mathrm{et} \mathrm{al.} \mathrm{Alterations} \mathrm{of} \mathrm{melatonin} \mathrm{receptors}$ MT1 and MT2 in the hypothalamic suprachiasmatic nucleus during depression. J Affect Disord. 2013;148(2-3):357-367.

25. Weston-Green K, Huang XF, Deng C. Alterations to melanocortinergic, GABAergic and cannabinoid neurotransmission associated with olanzapine-induced weight gain. PLoS One. 2012;7(3):e33548.

26. Romo-Nava F, Alvarez-Icaza González D, Fresán-Orellana A, et al. Melatonin attenuates antipsychotic metabolic effects: an eight-week randomized, double-blind, parallel-group, placebo-controlled clinical trial. Bipolar Disord. 2014;16(4):410-421.
27. Kiss A, Bundzikova J, Pirnik Z, Mikkelsen JD. Different antipsychotics elicit different effects on magnocellular oxytocinergic and vasopressinergic neurons as revealed by Fos immunohistochemistry. $J$ Neurosci Res. 2010;88(3):677-685.

28. Buijs RM, Scheer FA, Kreier F, et al. Organization of circadian functions: interaction with the body. Prog Brain Res. 2006;153:341-360.

29. Liu C, Weaver DR, Jin X, et al. Molecular dissection of two distinct actions of melatonin on the suprachiasmatic circadian clock. Neuron. 1997;19(1):91-102.

30. Kreier F, Fliers E, Voshol PJ, et al. Selective parasympathetic innervation of subcutaneous and intra-abdominal fat-functional implications. J Clin Invest. 2002;110(9):1243-1250.

31. Agil A, Navarro-Alarcón M, Ruiz R, Abuhamadah S, El-Mir MY, Vázquez GF. Beneficial effects of melatonin on obesity and lipid profile in young Zucker diabetic fatty rats. $J$ Pineal Res. 2011;50(2): 207-212.

32. Rasmussen DD, Boldt BM, Wilkinson CW, Yellon SM, Matsumoto AM. Daily melatonin administration at middle age suppresses male rat visceral fat, plasma leptin, and plasma insulin to youthful levels. Endocrinology. 1999;140(2):1009-1012.

33. Prunet-Marcassus B, Desbazeille M, Bros A, et al. Melatonin reduces body weight gain in Sprague Dawley rats with diet-induced obesity. Endocrinology. 2003;144(12):5347-5352.

34. Modabbernia A, Heidari P, Soleimani R, et al. Melatonin for prevention of metabolic side-effects of olanzapine in patients with first-episode schizophrenia: randomized double-blind placebo-controlled study. J Psychiatr Res. 2014;53:133-140.

35. Agil A, Rosado I, Ruiz R, Figueroa A, Zen N, Fernández-Vázquez G. Melatonin improves glucose homeostasis in young Zucker diabetic fatty rats. J Pineal Res. 2012;52(2):203-210.

36. Hotamisligil GS. Inflammation and metabolic disorders. Nature. 2006;444(7121):860-867.

37. Tilg H, Moschen AR. Inflammatory mechanisms in the regulation of insulin resistance. Mol Med. 2008;14(3-4):222-231.

38. Weisberg SP, McCann D, Desai M, Rosenbaum M, Leibel RL, Ferrante AW Jr. Obesity is associated with macrophage accumulation in adipose tissue. $J$ Clin Invest. 2003;112(12):1796-1808.

39. Wu H, Ghosh S, Perrard XD, Feng L, et al. T-cell accumulation and regulated on activation, normal $\mathrm{T}$ cell expressed and secreted upregulation in adipose tissue in obesity. Circulation. 2007;115(8): 1029-1038.

40. Mensah GA, Mokdad AH, Ford E, et al. Obesity, metabolic syndrome, and type 2 diabetes: emerging epidemics and their cardiovascular implications. Cardiol Clin. 2004;22(4):485-504.

41. Dandona P, Ghanim H, Chaudhuri A, Dhindsa S, Kim SS. Macronutrient intake induces oxidative and inflammatory stress: potential relevance to atherosclerosis and insulin resistance. Exp Mol Med.2010; 42(4):245-253.

42. Koziróg M, Poliwczak AR, Duchnowicz P, Koter-Michalak M, Sikora J, Broncel M. Melatonin treatment improves blood pressure, lipid profile, and parameters of oxidative stress in patients with metabolic syndrome. J Pineal Res. 2011;50(3):261-266.

43. Rudic RD, McNamara P, Curtis AM, et al. BMAL1 and CLOCK, two essential components of the circadian clock, are involved in glucose homeostasis. PLoS Biol. 2004;2(11):e377.

44. Turek FW, Joshu C, Kohsaka A, et al. Obesity and metabolic syndrome in circadian Clock mutant mice. Science. 2005;308(5724): 1043-1045.

45. Shimba S, Ishii N, Ohta Y, et al. Brain and muscle Arnt-like protein-1 (BMAL1), a component of the molecular clock, regulates adipogenesis. Proc Natl Acad Sci U S A. 2005;102(34):12071-12076.

46. Korkmaz A, Topal T, Tan DX, Reiter RJ. Role of melatonin in metabolic regulation. Rev Endocr Metab Disord. 2009;10(4):261-270.

47. Rüger M, Scheer FA. Effects of circadian disruption on the cardiometabolic system. Rev Endocr Metab Disord. 2009;10(4):245-260.

48. Everson CA. Functional consequences of sustained sleep deprivation in the rat. Behav Brain Res. 1995;69(1-2):43-54. 
49. Lucassen EA, Rother KI, Cizza G. Interacting epidemics? Sleep curtailment, insulin resistance, and obesity. Ann N Y Acad Sci. 2012; 1264:110-134.

50. Cohrs S. Sleep disturbances in patients with schizophrenia: impact and effect of antipsychotics. CNS Drugs. 2008;22(11):939-962.

51. Sinnamon WB, Pivorun EB. Melatonin induces hypertrophy of brown adipose tissue in Spermophilus tridecemlineatus. Cryobiology. 1981;18(6):603-607.

52. Amir S. Retinohypothalamic tract stimulation activates thermogenesis in brown adipose tissue in the rat. Brain Res. 1989;503(1):163-166.

53. Amir S, Shizgal P, Rompré PP. Glutamate injection into the suprachiasmatic nucleus stimulates brown fat thermogenesis in the rat. Brain Res. 1989;498(1):140-144.

54. Tanida M, Gotoh H, Taniguchi H, et al. Effects of central injection of L-carnosine on sympathetic nerve activity innervating brown adipose tissue and body temperature in rats. Regul Pept. 2007;144(1-3): $62-71$

55. Glass JD, Lynch GR. Evidence for a brain site of melatonin action in the white-footed mouse, Peromyscus leucopus. Neuroendocrinology. 1982;34(1):1-6.

56. Thomas L, Purvis CC, Drew JE, Abramovich DR, Williams LM. Melatonin receptors in human fetal brain: 2-[(125)I]iodomelatonin binding and MT1 gene expression. J Pineal Res. 2002;33(4):218-224.

57. Stankov B, Cozzi B, Lucini V, Fumagalli P, Scaglione F, Fraschini F. Characterization and mapping of melatonin receptors in the brain of three mammalian species: rabbit, horse and sheep. A comparative in vitro binding study. Neuroendocrinology. 1991;53(3):214-221.

58. Gauer F, Masson-Pevet M, Pevet P. Melatonin receptor density is regulated in rat pars tuberalis and suprachiasmatic nuclei by melatonin itself. Brain Res. 1993;602(1):153-156.

59. Peschke E. Melatonin, endocrine pancreas and diabetes. J Pineal Res. 2008;44(1):26-40.

60. Hu C, Zhang R, Wang C, et al. Effects of GCK, GCKR, G6PC2 and MTNR1B variants on glucose metabolism and insulin secretion. PLoS One. 2010;5(7):e11761.

61. Tam CH, Ho JS, Wang Y, et al. Common polymorphisms in MTNR1B, G6PC2 and GCK are associated with increased fasting plasma glucose and impaired beta-cell function in Chinese subjects. PLoS One. 2010; 5(7):e11428.

62. Peschke E, Bähr I, Mühlbauer E. Melatonin and pancreatic islets: interrelationships between melatonin, insulin and glucagon. Int J Mol Sci. 2013;14(4):6981-7015.

63. Peschke E, Wolgast S, Bazwinsky I, Pönicke K, Muhlbauer E. Increased melatonin synthesis in pineal glands of rats in streptozotocin induced type 1 diabetes. J Pineal Res. 2008;45(4):439-448.

64. Rasmussen DD, Mitton DR, Larsen SA, Yellon SM. Aging-dependent changes in the effect of daily melatonin supplementation on rat metabolic and behavioral responses. J Pineal Res. 2001;31(1):89-94.

65. Anderson RA, Evans ML, Ellis GR, et al. The relationships between post-prandial lipaemia, endothelial function and oxidative stress in healthy individuals and patients with type 2 diabetes. Atherosclerosis. 2001;154(2):475-483.
66. Sparks JD, Phung TL, Bolognino M, et al. Lipoprotein alterations in 10- and 20-week-old Zucker diabetic fatty rats: hyperinsulinemic versus insulinopenic hyperglycemia. Metabolism. 1998;47(11):1315-1324.

67. Korkmaz A, Reiter RJ, Topal T, Manchester LC, Oter S, Tan DX. Melatonin: an established antioxidant worthy of use in clinical trials. Mol Med. 2009;15(1-2):43-50.

68. Hoyos M, Guerrero JM, Perez-Cano R, et al. Serum cholesterol and lipid peroxidation are decreased by melatonin in diet-induced hypercholesterolemic rats. J Pineal Res. 2000;28(3):150-155.

69. Sener G, Balkan J, Cevikbaş U, Keyer-Uysal M, Uysal M. Melatonin reduces cholesterol accumulation and prooxidant state induced by high cholesterol diet in the plasma, the liver and probably in the aorta of C57BL/6J mice. J Pineal Res. 2004;36(3):212-216.

70. Sener A, Ozsavci D, Bingol-OzakpinarO, Cevik O, Yanikkaya-DemirelG, Yardimci T. Oxidized-LDL and Fe3+/ascorbic acid-induced oxidative modifications and phosphatidylserine exposure in human platelets are reduced by melatonin. Folia Biol (Praha). 2009;55(2):45-52.

71. Hussain SA. Effect of melatonin on cholesterol absorption in rats. J Pineal Res. 2007;42(3):267-271.

72. Müller-Wieland D, Behnke B, Koopmann K, Krone W. Melatonin inhibits LDL receptor activity and cholesterol synthesis in freshly isolated human mononuclear leukocytes. Biochem Biophys Res Commun. 1994;203(1):416-421.

73. Chan TY, Tang PL. Effect of melatonin on the maintenance of cholesterol homeostasis in the rat. Endocr Res. 1995;21(3):681-696.

74. Bongiorno D, Ceraulo L, Ferrugia M, Filizzola F, Ruggirello A, Liveri VT. Localization and interactions of melatonin in dry cholesterol/ lecithin mixed reversed micelles used as cell membrane models. J Pineal Res. 2005;38(4):292-298.

75. Scheer F. Daily night time melatonin reduces blood pressure in male patients with essential hypertension. Hypertension. 2004;43: 192-197.

76. Anan F, Takahashi N, Ooie T, Yufu K, Saikawa T, Yoshimatsu H. Role of insulin resistance in nondipper essential hypertensive patients. Hypertens Res. 2003;26(9):669-676.

77. Reiter RJ, Tan DX, Korkmaz A. The circadian melatonin rhythm and its modulation: possible impact on hypertension. J Hypertens Suppl. 2009;27(6):S17-S20.

78. Nava M, Quiroz Y, Vaziri N, Rodriguez-Iturbe B. Melatonin reduces renal interstitial inflammation and improves hypertension in spontaneously hypertensive rats. Am J Physiol Renal Physiol. 2003;284(3): F447-F454

79. Girouard H, Denault C, Chulak C, de Champlain J. Treatment by $\mathrm{n}$-acetylcysteine and melatonin increases cardiac baroreflex and improves antioxidant reserve. Am J Hypertens. 2004;17(10):947-954.

80. Kong D, Vong L, Parton LE, et al. Glucose stimulation of hypothalamic $\mathrm{MCH}$ neurons involves $\mathrm{K}(\mathrm{ATP})$ channels, is modulated by UCP2, and regulates peripheral glucose homeostasis. Cell Metab. 2010; 12(5):545-552.

81. Baptista T, ElFakih Y, Uzcátegui E, et al. Pharmacological management of atypical antipsychotic-induced weight gain. CNS Drugs. 2008;22(6):477-495.
Neuropsychiatric Disease and Treatment

\section{Publish your work in this journal}

Neuropsychiatric Disease and Treatment is an international, peerreviewed journal of clinical therapeutics and pharmacology focusing on concise rapid reporting of clinical or pre-clinical studies on a range of neuropsychiatric and neurological disorders. This journal is indexed on PubMed Central, the 'PsycINFO' database and CAS,
Dovepress

and is the official journal of The International Neuropsychiatric Association (INA). The manuscript management system is completely online and includes a very quick and fair peer-review system, which is all easy to use. Visit http://www.dovepress.com/testimonials.php to read real quotes from published authors. 